\title{
Ground improvement using granular pile anchor system: resistance to heave and uplift pressure
}

\author{
Alvin John Lim Meng Siang ${ }^{1}$, Ehab Hamad Sfoog ${ }^{2}$, Nahla Naji ${ }^{3}$, Sim Sy Yi ${ }^{4}$, Nickholas Anting Anak \\ Guntor $^{5}$, Joewono Prasetijo ${ }^{6}$ \\ ${ }^{1,2}$ Research Center for Soft Soils, Faculty of Civil and Environmental Engineering, University Tun Hussein Onn, Malaysia \\ ${ }^{3}$ Faculty of Engineering, Anbar University, Iraq \\ 4,6Faculty of Engineering Technology, University Tun Hussein Onn Malaysia, Malaysia \\ ${ }^{5}$ Faculty of Civil and Environmental Engineering, Universiti Tun Hussein Onn, Malaysia
}

\section{Article Info}

Article history:

Received Dec 14, 2019

Revised Feb 3, 2020

Accepted Feb 20, 2020

\section{Keywords:}

Granular pile anchor (GPA)

Numerical testing

\begin{abstract}
Expansive soil is found in many parts of the world where its major drawback is its expansion and shrinking property upon moisture absorption and drying during alternation of rainy-dry seasons. Due to its swelling-shrinkage repeated process, fatigue and distress cause crack to structures. Granular pile anchor (GPA) system is a pioneering technique that is utilised in reinforcing these expansive soils. GPA system is a pioneering technique that is utilised in reinforcing expansive soils. The GPA provides tensile resistance which arrest the exerted upward forces and hence reducing heave. Previous investigations have only focused on load-displacement relationships by utilizing the pull-out technique. In this technique, an external force pulls the GPA and the corresponding displacements are recorded. The results provide indication of the GPA resistance to the applied force. However, in real conditions the heave and expansion forces were developed as a result of the pressure caused by the water absorption which pushes the entire soil bed in the upward direction along with the GPA. Therefore, this paper is aimed to explore this concept by carrying experimental and numerical investigations on a small scale model for a single pile with a diameter of $4 \mathrm{~cm}$, with lengths of 20 and $40 \mathrm{~cm}$. Ultimately, the reinforced soil exhibits reduction in upward force and heave compared to the unreinforced soil. Also, verifications for the testing shows that the relationship between the upward force and heave exhibits almost linear relationship for both experimental and numerical investigations. Therefore, shallow foundations incorporated with a GPA system proves to effectively lessen the heave that occurs in expansive soils which in turn can solve problems for constructions.
\end{abstract}

Copyright (C) 2020 Institute of Advanced Engineering and Science. All rights reserved.

\section{Corresponding Author:}

Alvin John Lim Meng Siang, Research Center for Soft Soils, Faculty Of Civil and Environmental Engineering,

Department of Civil Engineering, University Tun Hussein Onn, 86400, Parit Raja, Johor, Malaysia.

Email: alvin@uthm.edu.my

\section{INTRODUCTION}

Expansive soils are considered to be very problematic as they inherently undergo volume changes with moisture content changes [1]. The indication of the exsitence of expansive soil can be distinguished effectively by various site investigation techniques that correlates its phycial characteristics to engineering parameters such as elastic modulus, shear modulus and Poisson's ratio etc. [2] The main physical characteritic behaviour of expansive soils is that it expands when it asorbs water and shrinks when it looses water [3, 4]. 
Due to this dual repetitions, civil engineering structures such as residential buildings, pavement, sidewalks and lightweight structures constructed on such soil that resist movements from the soil are severely damaged resulting in enormous economic losses [5]. The cost in repairing the damage or constructing new structures with stonger concreting works urged for more viable remedies prior to foundation construction [6].

Various techniques were suggested for remedying the swell-shrink problems which can be categorized as physical alteration (i.e. soil replacement), chemical alteration (i.e. chemical binders; cement and lime) and tension-resistant foundations (i.e. granular pile anchor) [7]. The granular pile anchor (GPA) is a cost-effective technique that gain attention in recent years. Generally the GPA is superior in expansive soils due to its advantage in resisting the tensile forces triggered by water absorbtion. Numerious studies were conducted using GPA in the laboratory as well as in the field at large scale supported by numerical analysis. Among the early studies on the GPA system comes from the laboratory investigation carried out by [8]. More recent studies have been conducted on GPA with various parameters to investigate based on geosynthetic pullout load and rate of heave [9, 10]; pullout in field-scale [7]; heave in field study [11, 12]; heave and uplift [13]; cycles of swelling and shrinkage [14]; geogrid reinforcement on uplift capacity [15]; uplift capacity [16]; relative density of GPA fill material and encasement effects on the pull capacity [17]; comparison between the GPA and helical pile anchors [18]; geosynthetic encasement [19]; and pullout forces [20, 21].

Most of the previous studies that focused on load-displacement relationship utilize the pullout technique where the GPA is pulled upward and the corresponding displacement is recorded. These results can provide indication of the GPA resistance to the applied force. However, in real conditions the heave and expansion forces are developed as a result of the pressure caused by the water absorption which pushes the entire soil bed along with the GPA in the upward direction. Therefore, this paper is aimed to explore this concept of external forces from soil pressure subjected to the pile by performing experimental and numerical investigations in a small scale model on a single pile with a diameter of $4 \mathrm{~cm}$ with lengths of $20 \mathrm{~cm}$ and $40 \mathrm{~cm}$. The experimental and numerical investigations were carried out to validate the outcome of the test.

Table 1. Physical properties of expansive soil

\begin{tabular}{cc}
\hline Variable & Speed (rpm) \\
\hline Soil Property & Value \\
Specific Gravity (Gs) & 2.73 \\
Liquid limit (LL) \% & 59 \\
Plastic limit (P.L) \% & 23 \\
Plasticity Index (PI) \% & 36 \\
\% Clay & 51 \\
\% Silt & 42 \\
\% Sand & 7 \\
\% Gravel & 0 \\
(USCS) CH & $\mathrm{CH}$ \\
Unified Soil Classification System & 1.93 \\
Organic Matters Content $(\%)$ & 1.85 \\
Gypsum Content (\%) & 1.05 \\
Total Soluble Salts Content $(\%)$ & 0.86 \\
Sulphate (SO3) Content $(\%)$ & 16.3 \\
Maximum Unit Weight $\left(\gamma_{d r y}\right), \mathrm{kN} / \mathrm{m}^{3}$ & 21.5 \\
Optimum Moisture Content $(\mathrm{OMC}) \%$ & 0.674 \\
Initial Void Ratio (eo) & 48.3 \\
Montmorillonite & 30.6 \\
Illite & 21.1 \\
Kaolinite &
\end{tabular}

Table 2. Summary of sand properties

\begin{tabular}{cc}
\hline Property & Value \\
\hline Specific Gravity $(\mathrm{Gs})$ & 2.66 \\
D10 & 0.18 \\
D60 & 0.31 \\
Coefficient of Uniformity $(\mathrm{Cu})$ & 0.50 \\
Coefficient of Curvature $(\mathrm{Cc})$ & 2.79 \\
Classification System $(\mathrm{USCS})$ & 1.06 \\
Maximum Unit Weight $\left(\gamma_{\max }\right), \mathrm{kN} / \mathrm{m}^{3}$ & $\mathrm{SP}$ \\
Minimum Unit Weight $\left(\gamma_{\min }\right), \mathrm{kN} / \mathrm{m}^{3}$ & 18.10 \\
Experimental Relative Density $(\mathrm{Dr})$ & 73.60 \\
Experimental Unit Weight $\left(\gamma_{d r y}\right), \mathrm{kN} / \mathrm{m}^{3}$ & 16.72 \\
Maximum Void Ratio $(\mathrm{emax})$ & 0.96 \\
Minimum Void Ratio $(\mathrm{emim})$ & 0.47 \\
Experimental Void Ratio $(\mathrm{eo})$ & 0.59 \\
Cohesion $(\mathrm{c}), \mathrm{kPa}$ & 0 \\
Angle of Shearing Resistance $(\varnothing)^{\circ}$ & 40 \\
Organic Matters Content $(\%)$ & 0.31 \\
Gypsum Content $(\%)$ & 0.78 \\
Total Soluble Salts Content $(\%)$ & 0.88 \\
Sulphate $($ SO3) Content $(\%)$ & 0.36 \\
\hline
\end{tabular}

\section{RESEARCH METHOD}

Small scale model for experimental physical and numerical modelling techniques were used to investigate the viability of the granular pile anchor to improve expansive soils in terms of heave and uplift forces. The numerical model has been used to validate the described problem from the experimental physical model in the laboratory. A finite element software program of PLAXIS 3D-Version 2013 was used based on the adopted non-linear elastoplastic model.

\subsection{Material used}

The expansive soil used in this study was obtained from the site work which is anticipated for the constructing of a low cost building at Musyyb Babil province which is located in the middle of Iraq. The soil was collected from depths between (0.5-2) m below the natural ground surface which is within the depth of unsaturated soil during the dry season. The index properties of expansive soil are summarised in 
Table 1. It is obvious that this type of soil contains high percentage of fine particles with $7 \%$ of sand and the remaining content are $51 \%$ clay and $42 \%$ silt. In addition, the Atterberg limit test showed that liquid limit was obtained at $59 \%$ and plastic limit at $23 \%$ with plasticity index of $36 \%$. Therefore, according to the unified soil classification system (USCS), this type of soil is classified as high plasticity soil (CH). The specific gravity, maximum unit weight, optimum moisture content and initial void ratio were found to be $2.73,16.3 \mathrm{KN} / \mathrm{m} 3$, $21.5 \%$ and 0.674 respectively. The sand was used as a fill material (granular material) for the GPA. The index properties of sand are summarized in Table 2. Therefore, according to the unified soil classification system (USCS) the sand that was used is classified as poorly graded soil (SP). The purpose of using such sand is to provide frictional properties in order resistance for the soil expansion.

\subsection{Sample preparation}

The laboratory physical model was designed using a stainless-steel container with $4 \mathrm{~mm}$ thickness, $30 \mathrm{~cm}$ length, $30 \mathrm{~cm}$ width and $65 \mathrm{~cm}$ height as shown in Figure 1. Two main layers were prepared in the model to mimic the real site conditions. The first layer is the stable zone which is fully saturated. The expansive soil was mixed at a moisture content of $23.1 \%$ to obtain a degree of saturation at $94 \%$. The soil was compacted gently until $35 \mathrm{~cm}$ thickness was achieved. The second layer is the active zone which represents the unsaturated soil. The degree of saturation for this layer of soil was $70 \%$ with a moisture content of $18.3 \%$ which is the condition on site during the dry season. The soil was compacted until it achieves a thickness of $25 \mathrm{~cm}$. Initial testing was firstly done to determine the physical properties of the soil for its suitability in the testing.

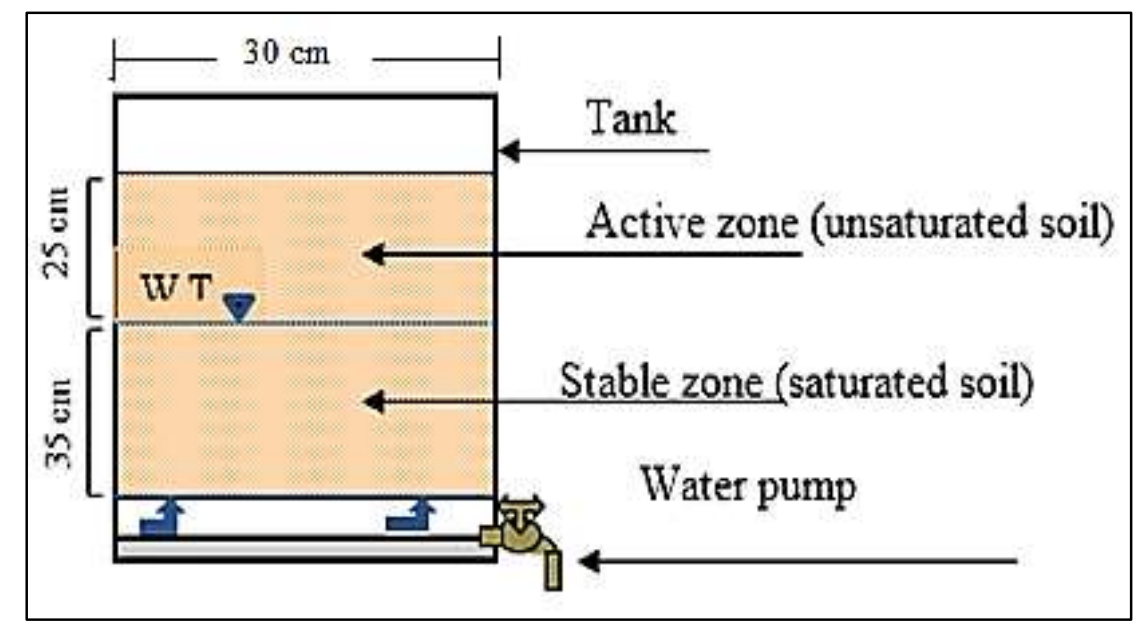

Figure 1. Soil bed preparation

\subsection{Granular pile anchor installation}

The granular pile anchor (GPA) was installed in the center of the expansive soil bed. A PVC pipe was driven carefully from the surface towards the bottom of the soil bed to make the hole for the GPA. The diameter of the GPA was fixed at $4 \mathrm{~cm}$ whereas the length varies at $20 \mathrm{~cm}$ and $40 \mathrm{~mm}$. The base plate along with the rod anchor was installed in the hole. Then, the sand was poured carefully in layers and taped gently with steel bar to ensure a compacted column around the rod anchor and adjusted in the expansive soil interface.

\subsection{Test procedure}

The experiment setup which includes the loading compression machine and its components is shown in Figure 2. The heave test was performed initially on the plain expansive soil without GPA and then with GPA. For all samples, the water was allowed to flow through the soil bed until the soil was fully saturated. The soil was allowed to expand under wetting to reach the equilibrium state where there is no further expansion. In order to find the swelling pressure, incremental loading was applied on the sample until it achieves the initial stage of expansion. This test was conducted in accordance to the one-dimensional swelling or collapsing of cohesive soils (ASTM D4546-08). This testing was conducted to obtain the ultimate uplift force which is equivalent to the force required to bring back the sample height to the original condition before the expansion occurred. The numerical modeling was done with the dimensions and condition that are the same with the physical modeling as shown in Figure 3. 


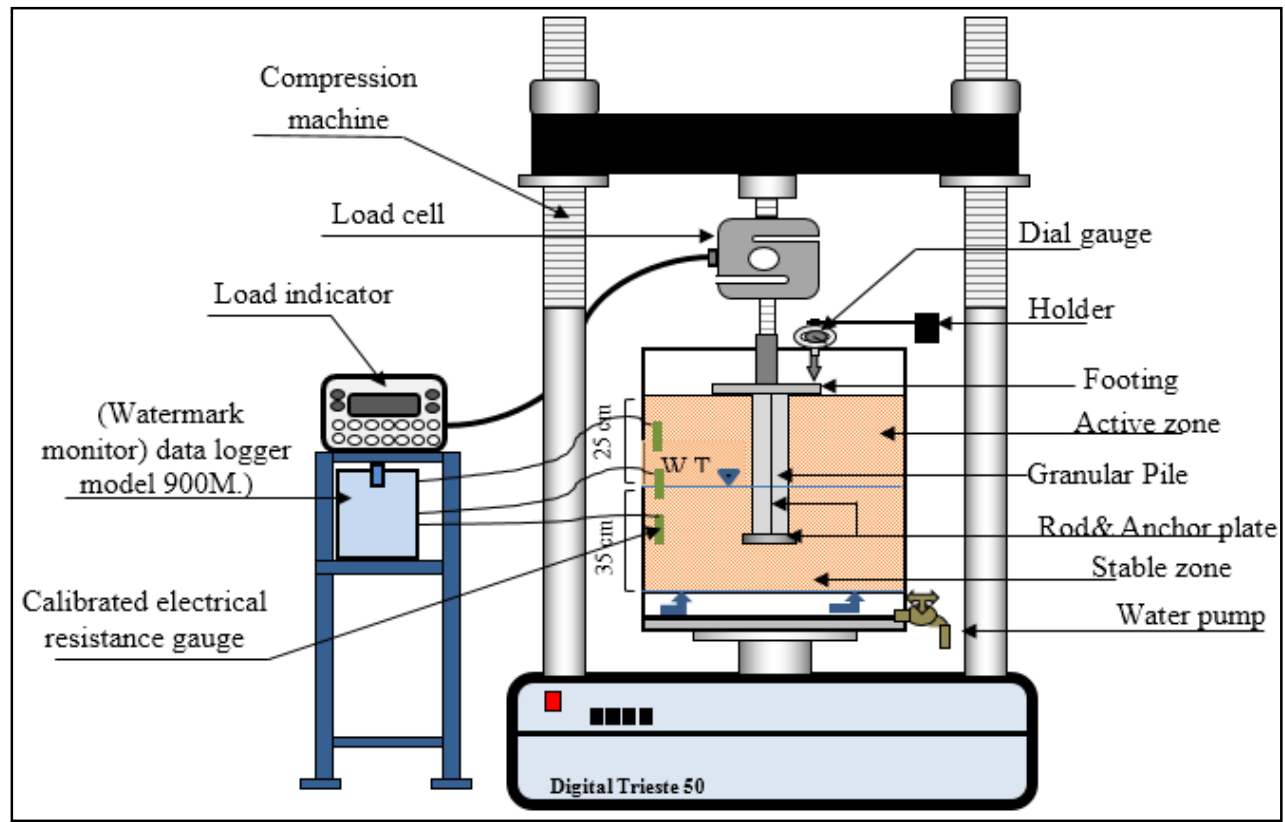

Figure 2. Testing setup for the experimental physical modelling

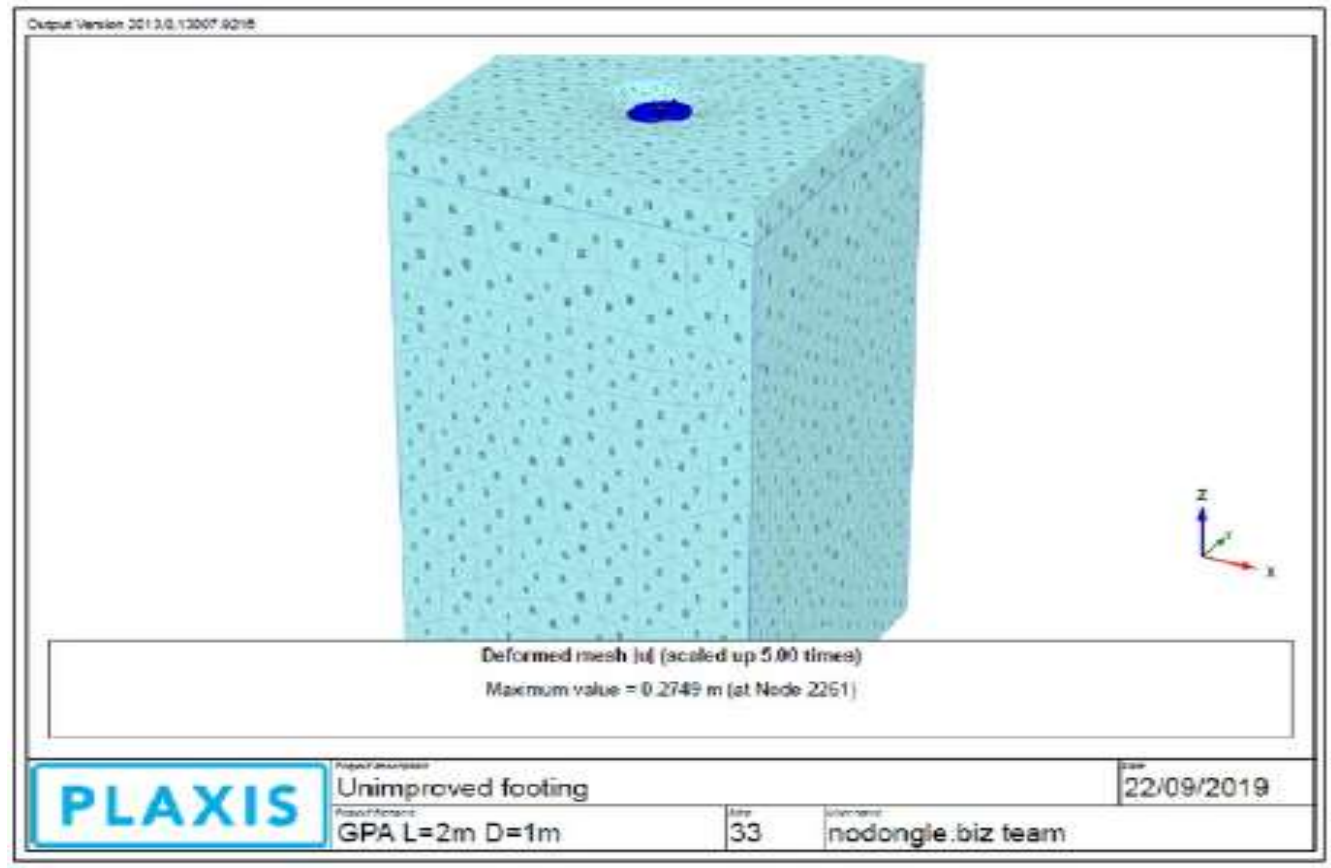

Figure 3. Testing setup for the numerical modelling using PLAXIS 3D

\section{RESULTS AND DISCUSSIONS}

Before the modelling test was done, initial testing such as odometer and proctor compaction testing was done to obtain the physical properties of the soil. This was done to identify the soil conditions which will be used to simulate the real site conditions for the physical and numerical testing.

\subsection{Degree of Saturation}

The degree of saturation for the expansive soil was tested at various moisture content and correlated with the shear strength using the vane shear test and the results are shown in Figure 4 . The shear strength 
decreased significantly as the moisture content increased. The expansive soil was prepared at $70 \%$ degree of saturation which is the degree of saturation found in the site condition during the dry season. It is the critical limit where the soil is prone to maximum expansion when the soil saturation reaches $94 \%$. A study conducted by Kong \& Tan [22] showed that the shear strength decreased from $42 \mathrm{kPa}$ and $80 \mathrm{kPa}$ when the moisture content decreased between $31.6 \%$ and $41.2 \%$.

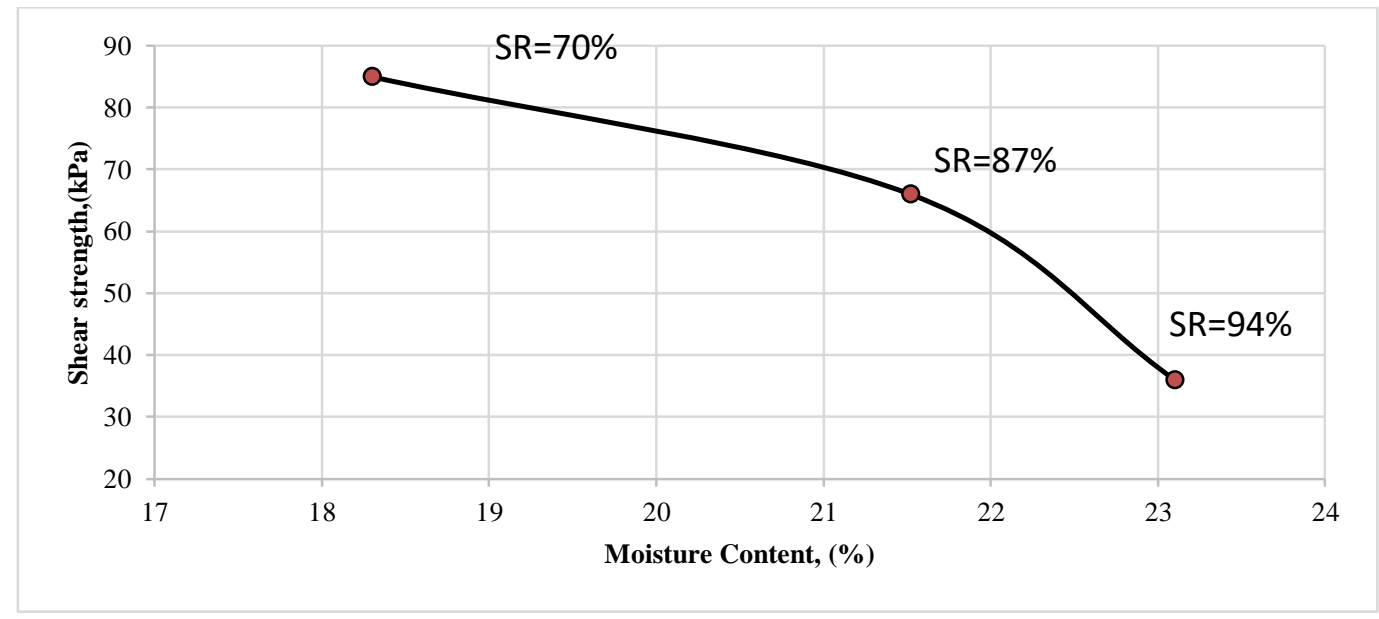

Figure 4. Degree of saturation at different moisture content

\subsection{Mechanical properties}

The mechanical properties of the expansive soil are shown in Table 3. The shear strength of the expansive soil was investigated under drained condition. The drained cohesion ( $\left.\mathrm{c}^{\prime}\right)$ and angle of internal friction $\left(\emptyset^{\prime}\right)^{\circ}$ using consolidated drained triaxial, at adjusted velocity of $0.02 \mathrm{~mm} / \mathrm{min}$, were $30 \mathrm{kPa}$ and 22 respectively. The compression index $(\mathrm{Cc})$ for this type of soil was 0.332 . The swell and collapse behavior is shown in Figure 5(a). The soil was allowed to swell until maximum value was achieved which is equivalent to $6.6 \%$ of the total sample height. Then, incremental load was applied to compress the soil and determine the swell pressure. The swelling pressure was obtained at $205 \mathrm{kPa}$ which is the pressure that would prevent swelling. The maximum dry density was found to be $16.3 \mathrm{kN}$ which corresponds to a moisture content of 21.5 $\%$ as shown in Figure 5(b).

Table 3. Mechanical properties of expansive soil

\begin{tabular}{ccc}
\hline Test Name & Soil Property & Value \\
\hline Consolidated Drained & Drained Cohesion $\left(\mathrm{c}^{\prime}\right), \mathrm{kPa}$ & 30 \\
Triaxial (CD at $(0.02$ & & \\
mm/min) adjusted & Drained Angle of Internal Friction $\emptyset$ & 22 \\
Velocity & Compression Index (Cc) & 0.332 \\
One-Dimensional & Swelling Index (Cs) & 0.076 \\
Swell or Consolidation & Free Swelling (\%) & $6.6 \%$ \\
& Swelling Pressure (kPa) & 205 \\
\hline
\end{tabular}

\subsection{Heave-Force Relationship}

The upward force resulted from swelling pressure was investigated experimentally and numerically. Many studies [7, 9, 15-17, 23-26] have been conducted to investigate the displacement resulted from the application of external force to pull the GPA. The numerical investigation is an essentially part of the research so as to have an accurate interpretation of the results [27-29]. Normally, the upward displacement is recorded with respective incremental pull-out forces. This process continues until the GPA fails. This technique can provide quantified indication (displacement record) about the GPA resistance ability to the applied uplift force. Nonetheless, it does not reflect the real forces which are resulted from the pore water pressure causing the soil expansion with time. 
Therefore, the developed net force within the expansive soil that causes the heave was explored in the current investigation. Heave was done on the physical testing by pumping water at the bottom of the model and letting the soil to have a degree of saturation of $70 \%$. Uplift force then was recorded by using a compression machine where the maximum uplift force is considered equal to the force to compress the sample back to its original sample height.

The numerical and experimental physical modelling results are shown in Figures 6 (a) and (b) respectively. Generally, the reinforced soil exhibits reduction in upward force and heave compared to the unreinforced soil. The relationship between the upward force and heave exhibits almost linear relationship for both experimental physical and numerical investigations as shown in Figure 7. Table 4 shows the improvement and the percentage of similarity between the numerical and experimental physical modelling of all the test. These results show a maximum of $50 \%$ heave reduction for the reinforced soil compared to the unreinforced soil. On the other hand, the application of the GPAs was able to arrest the resulted upward forces significantly. The reduction in upward force was almost $60 \%$. Incorporating the anchor system provide resistance to the tensile forces caused by the water absorption.

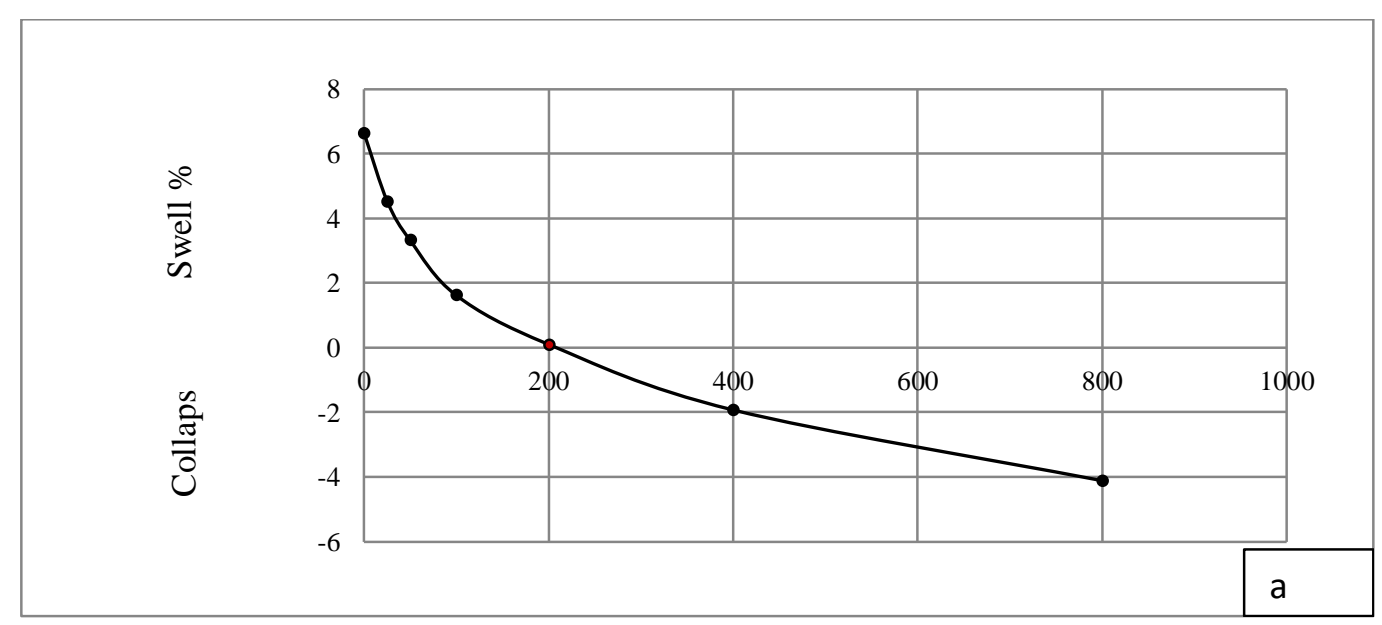

Figure 5. (a) 1-Dimensional consolidation

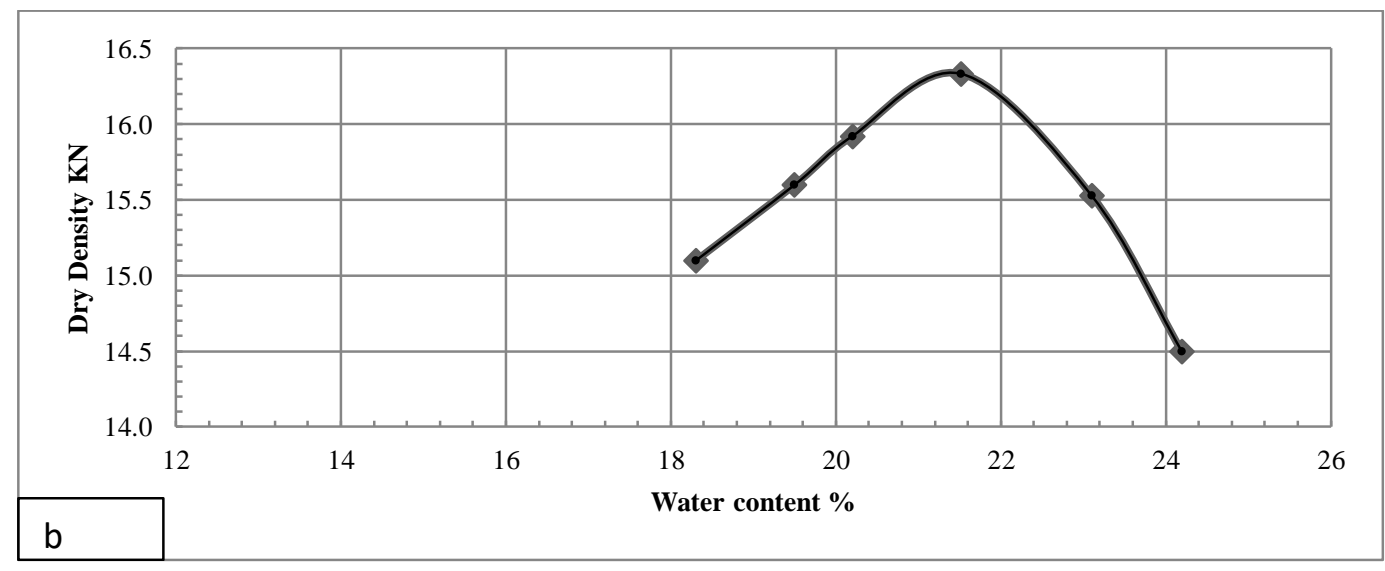

Figure 5. (b) Dry density (continue) 


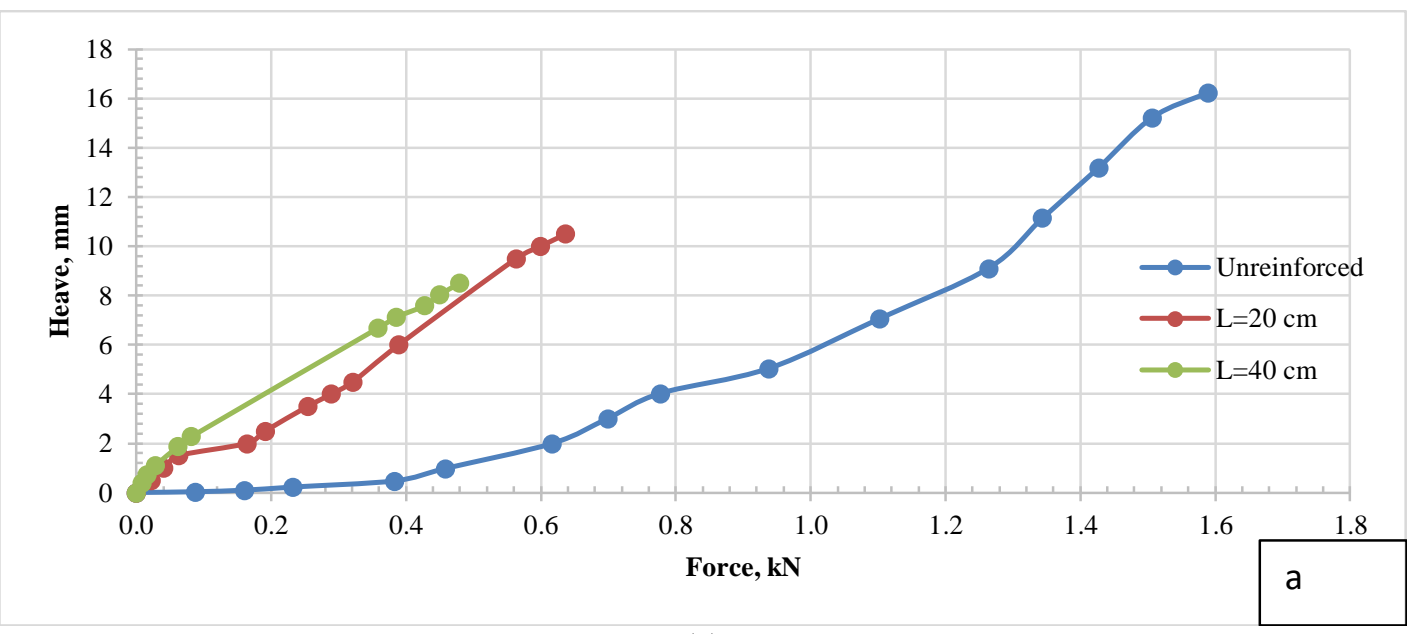

(a)

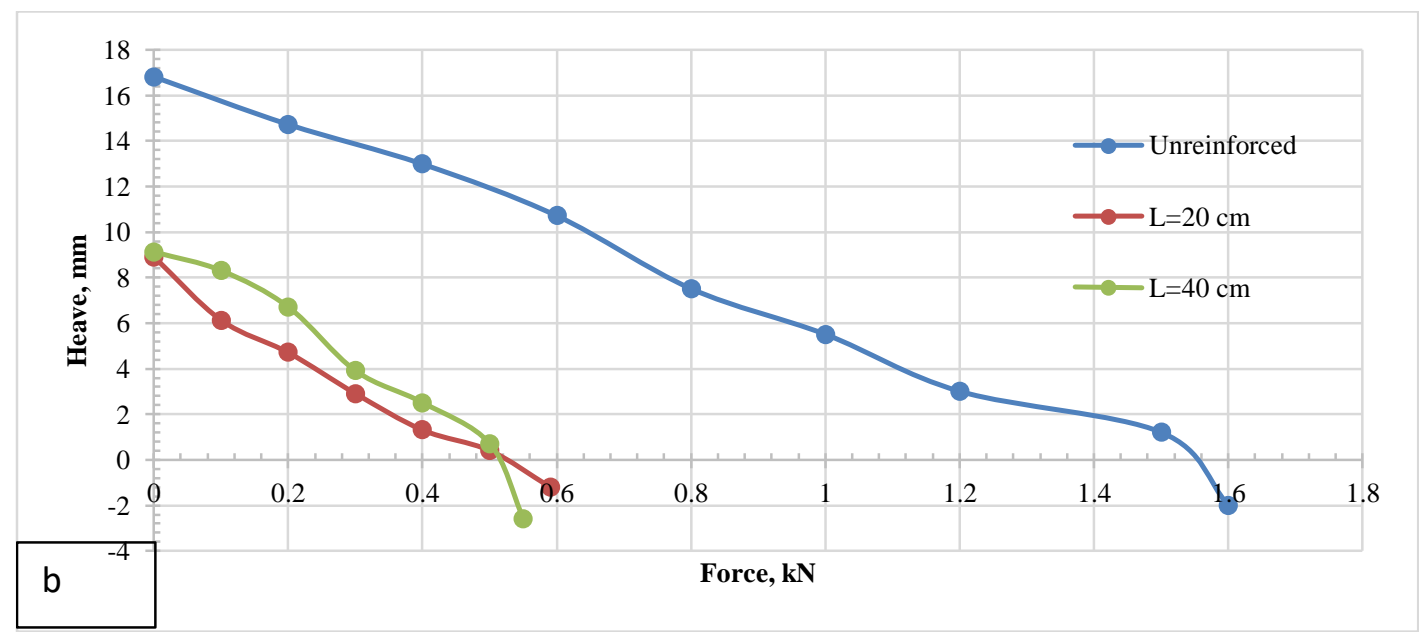

(b)

Figure 6. Heave vs force relationship, (a) numerical (b) experimental (continue)

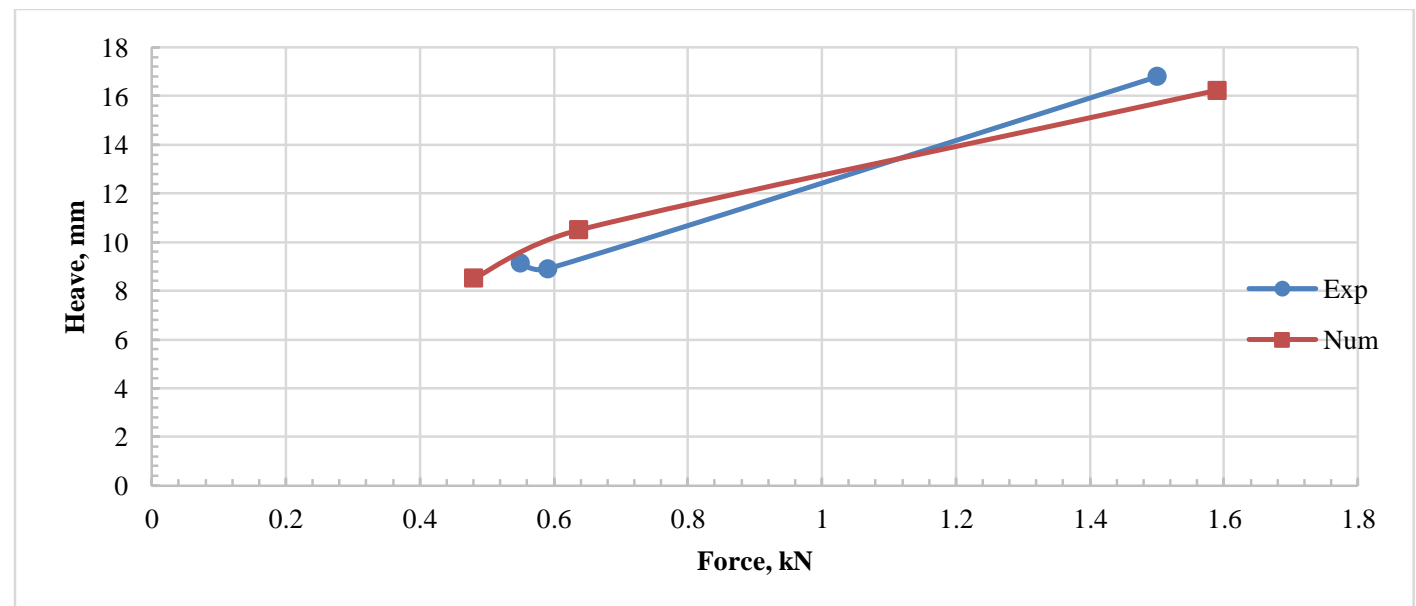

Figure 7. Maximum heave vs force for experimental and numerical analysis 
Table 4. Summary of the experimental and numerical results

\begin{tabular}{cccccccc}
\hline $\mathrm{L}(\mathrm{cm})$ & $\mathrm{D}(\mathrm{cm})$ & & \multicolumn{3}{c}{ Heave $(\mathrm{mm})$} & \multicolumn{3}{c}{ Uplift Force kN } \\
& & Experimental & Numerical & Similarity $\%$ & Experimental & Numerical & Similarity \% \\
\hline Unreinforced & 4 & 16.8 & 16.2 & 96.4 & 1.5 & 1.59 & 94.4 \\
20 & & 8.9 & 10.5 & 84.8 & 0.57 & 0.63 & 89.5 \\
40 & & 9.12 & 8.5 & 93.2 & 0.55 & 0.48 & 87.2 \\
\hline
\end{tabular}

\section{CONCLUSION}

This paper presents a small-scale laboratory test that was conducted to investigate the behavior of a GAP in expansive soil. The results were compared with finite-element analysis using PLAXIS 3D. The diameter of the GPA was fixed at $4 \mathrm{~cm}$ and length $20 \mathrm{~cm}$ and $40 \mathrm{~cm}$. The net upward force-heave relationship developed by the soil expansion process was explored. Based on the obtained results, it is found that the upward force of the expansive soil results in almost in a linear relationship with heave. The force-heave is also seen to be reduced significantly with the incorporation of GPA. These results show a maximum of $50 \%$ heave reduction for the reinforced soil compared to the unreinforced soil. On the other hand, the application of the GPAs was able to arrest the resulted upward forces significantly. The reduction in upward force was almost $60 \%$. Incorporating the anchor system provide resistance to the tensile forces caused by the water absorption. The similarity between the experimental between experimental and numerical results for heave are $96.4 \%, 84.8 \%$ and $93.2 \%$ for unreinforced, $20 \mathrm{~cm}$ and $40 \mathrm{~cm}$ length of GPA respectively. The similarity between the experimental and numerical results for upward force however are $94.4 \%, 89.5 \%$ and $87.2 \%$ for unreinforced, $20 \mathrm{~cm}$ and $40 \mathrm{~cm}$ length of GPA respectively.

Hence this study proves to accurately measure the effectiveness of having GPA to reduce heave and uplift forces which can cause damages to structures. The technique used is a direct representation of what is happening in real site conditions during heave and shrinking of the soil where the soil pressure is used to measure the uplift force of the pile rather than the pull out force of the pile which is not accurate as it was tested by other researchers.

\section{ACKNOWLEDGEMENTS}

The authors would like to acknowledge Universiti Tun Hussein Onn Malaysia (UTHM) and and the Ministry of Higher Education (MOHE) for the financial support for this study under the research grant FRGS VOT. 1626.

\section{REFERENCES}

[1] Chen, F. H, "Foundations on expansive soils," Elsevier, vol. 12, 2012.

[2] Madun, A., et al., "Convertion shear wave velocity to standard penetration resistance," IOP Conf. Series: Materials Science and Engineering, vol. 136, no. 1, pp. 1-7, 2016.

[3] Nelson, J., and Miller, D. J, "Expansive soils: Problems and practice in foundation and pavement engineering," John Wiley \& Sons, 1997.

[4] Lu, N., and Likos, W. J, "Unsaturated soil mechanics," Wiley, 2004.

[5] Siang, A. J. L. M., et al., "Innovative laboratory assessment of the resilient behaviour of materials (Rigid, Elastic and Particulates)," Procedia Engineering, vol. 53, pp. 156-166, 2012.

[6] Azmi, N. B., et al., "A study on the performance of concrete containing recycled aggregates and ceramic as materials replacement," IOP Conf. Series: Materials Science and Engineering, vol. 271, pp. 1-9, 2017.

[7] Rao, A. S., et al., "Pullout behavior of granular pile-anchors in expansive clay beds in situ," Journal of Geotechnical and Geoenvironmental Engineering, vol. 133, no. 5, pp. 531-538, 2007.

[8] Phanikumar, B. R, "A study of swelling characteristics of and granular pile anchor foundation system in expansive soils," Submitted to JN Technological University, 1997.

[9] Kumar, B. R. P., and Rao, N. R, "Increasing pull-out capacity of granular pile anchors in expansive soils using base geosynthetics," Canadian Geotechnical Journal, vol. 37, no. 4, pp. 870-881, 2000.

[10] Phanikumar, B. R., et al., "Granular pile anchor foundation (GPAF) system for improving the engineering behavior of expansive clay beds," Geotechnical Testing Journal, vol. 27, no. 3, pp. 279-287, 2004.

[11] Phanikumar, B. R., Srirama Rao, A., and Suresh, K., "Field behaviour of granular pile-anchors in expansive soils," Proceedings of the Institution of Civil Engineers-Ground Improvement, vol. 161, no. 4, pp. 199-206, 2008.

[12] Aljorany, A. N., Ibrahim, S. F., and Al-Adly, A. I., "Heave behavior of granular pile anchor-foundation system," Journal of Engineering, vol. 20, no. 4, pp. 1-22, 2014

[13] Phanikumar, B. R., and Muthukumar, M., "Reducing heave of expansive clay beds through granular pile-anchor groups," Proceedings of the Institution of Civil Engineers-Ground Improvement, vol. 167, no. 2, pp. 99-107, 2014.

[14] Phanikumar, B. R., and Muthukumar, M., Swelling behaviour of GPA-reinforced expansive clay beds subjected to swell-shrink cycles," Geomechanics and Geoengineering, vol. 10, no. 4, pp. 261-270, 2015. 
[15] Phanikumar, B. R., "Influence of geogrid reinforcement on pullout response of granular pile-anchors (GPAs) in expansive soils," Indian Geotechnical Journal, vol. 46, no. 4, pp. 437-444, 2016.

[16] Kranthikumar, A., et al., "Numerical and experimental investigations of granular anchor piles in loose sandy soil subjected to uplift loading," International Journal of Geomechanics, vol. 17, no. 2, 2016.

[17] Johnson, N., and Sandeep, M. N., "Ground improvement using granular pile anchor foundation," Procedia Technology, vol. 24, pp. 263-270, 2016.

[18] Muthukumar, M., and Shukla, S. K., "Comparative study on the behaviour of granular pile anchors and helical pile anchors in expansive soils subjected to swelling," International Journal of Geotechnical Engineering, pp. 1-6, 2017.

[19] Muthukumar, M., and Shukla, S. K., "Swelling behaviour of expansive clay beds reinforced with encased granular pile anchors," International Journal of Geotechnical Engineering, vol. 12, no. 2, pp. 109-117, 2018.

[20] Sharma, A., and Sharma, R. K., "An experimental study on uplift behaviour of granular anchor pile in stabilized expansive soil," International Journal of Geotechnical Engineering, pp. 1-14, 2019.

[21] Sharma, R. K., "A new foundation practice for predicting the behavior of granular pile anchor against uplift forces in expansive soils," International Conference on Sustainable Waste Management through Design, pp. 140-147, 2018.

[22] Kong, L. W., and Tan, L. R., "Study on shear strength and swelling-shrinkage characteristic of compacted expansive soil," Unsaturated Soils for Asia, pp. 515-519, 2000.

[23] Sivakumar, V., et al., "Granular anchors under vertical loading-axial pull," Canadian Geotechnical Journal, vol. 50, no. 2, pp. 123-132, 2012.

[24] O’Kelly, B. C., Brinkgreve, R. B. J., and Sivakumar, V., "Pullout resistance of granular anchors in clay for undrained condition," Soils and Foundations, vol. 54, no. 6, pp. 1145-1158, 2014.

[25] Ganasan, R., Lim, A. J. M. S., and Wijeyesekera, D. C., "Physical and software modelling for challenging soil structure interaction," ARPN Journal of Engineering and Applied Sciences, vol. 11, no. 6, pp. 3668-3676, 2016.

[26] Izzati Norazam, P. N. F., et al., "Stability of peat soil by using envirotac," Matec Web of Conferences, vol. 103, no. 5, 2017.

[27] Andreas G.S, Theocharis T., and Vassos S., "Intelligent On/Off dynamic link management fo on-chip networks," Journal of Electrical and Computer Engineering, vol 12, 2012.

[28] Zhang, Y., et al., "The channle compressive sensing estimation for power line based on OMP algortihm," Journal of Electrical and Computer Engineering, vol. 2017, 2017.

[29] Ahmad, A., et al., "Adaptive ANN based differential protective relay for reliable power transformer protection operation during energisation," International Journal of Artificial Intelligence, vol. 8, no. 4, 2019. 